\title{
Histological features of sclerosing cholangitis in patients with chronic ulcerative colitis
}

\author{
C BARBATIS, * P GRASES, $\S$ HA SHEPHERD $\uparrow$ RW CHAPMAN, $\dagger$ JOAN TROWELL $\ddagger$ \\ DPJ JEWELL, $\dagger$ JO' D MCGEE§
}

From the *Department of Histopathology, Lewisham Hospital, London, and the †Department of Gastroenterology and Nuffield Departments of $¥$ Medicine and \$Pathology, John Radcliffe Hospital, Oxford

SUMMARY Primary sclerosing cholangitis was diagnosed radiologically in 16 of 681 patients $(2 \cdot 2 \%)$ with chronic ulcerative colitis in a follow up study at the gastroenterology unit in Oxford. On the basis of established histological criteria, the liver biopsy was considered diagnostic in only half of the cases. The histological findings in these cases were therefore reassessed to determine whether the accuracy of biopsy diagnosis could be improved. The most common specific histological feature was periductal concentric fibrosis of small interlobular bile ducts, even in the absence of inflammation. Other common features were bile ductular proliferation associated with diminution or absence of interlobular bile ducts. Degeneration of bile duct epithelium and diffuse infiltration of portal tracts by mononuclear cells and polymorphonuclear leucocytes were accompanying features. Piecemeal necrosis without rosette formation was found in about half the biopsies. When all these features were considered together a biopsy diagnosis of primary sclerosing cholangitis was established in 14 of 16 cases.

Primary sclerosing cholangitis is a chronic fibrosing inflammation of the extrahepatic bile ducts, with or without involvement of the intrahepatic bile ducts ${ }^{1-3}$ and in the absence of choledocholithiasis, sequela of biliary tract surgery, cholangiocarcinoma, or congenital biliary anomalies. ${ }^{45}$ It is associated with chronic ulcerative colitis, being found in $3-4 \%$ of patients with the disorder. ${ }^{67}$ As the disease is segmental and the histological features non-specific, ${ }^{8}$ the role of liver biopsy is equivocal. Some features overlap those seen in extrahepatic biliary obstruction, chronic active hepatitis, and even primary biliary cirrhosis. This has given rise to a number of alternative designations for primary sclerosing cholangitis based on morphological criteria such as interlobular hepatitis, ${ }^{,}$intrahepatic cholangiolitic hepatitis, ${ }^{10}$ portal triaditis, ${ }^{11}$ pericholangitis, ${ }^{12}$ and chronic non-suppurative obliterative cholangitis. ${ }^{13}$

In view of the apparent difficulty in establishing a tissue diagnosis of primary sclerosing cholangitis the present study was undertaken in an attempt to delineate those morphological features which are helpful in the diagnosis of primary sclerosing cholangitis associated with ulcerative colitis.

Accepted for publication 27 March 1985

\section{Patients and methods}

Of 681 patients with chronic ulcerative colitis taking part in a follow up study at the gastroenterology unit in Oxford, $16(2.2 \%)$ had radiological evidence of primary sclerosing cholangitis. ${ }^{7}$ Fifteen patients were examined by endoscopic retrograde cholangiopancreatography and one by percutaneous transhepatic cholangiography; there were 11 men and five women aged between 22 and 77 years (mean 47 years). The mean duration of colitis was 11.7 years (range 10 months to 26 years), and in three patients the liver dysfunction preceded symptomatic ulcerative colitis by two, three, and 15 years. Two patients had undergone colectomy five and 10 years before results of liver function tests were found to be abnormal. The colitis in all patients was symptomatically mild; nine had total colitis, six had disease of the left colon, and one had proctitis only. All patients were taking low doses of sulphasalazine and two were taking corticosteroids for previously diagnosed chronic active hepatitis. The clinical details of these patients have been reported elsewhere.?

HISTOLOGICAL METHODS

All patients with primary sclerosing cholangitis had had at least one liver biopsy, which had been 
Table 1 Original biopsy diagnosis in patients with radiologically proved primary sclerosing cholangitis

\begin{tabular}{ll}
\hline Diagnosis & No of cases \\
\hline Primary sclerosing cholangitis & 8 \\
Chronic active hepatitis & 4 \\
Primary biliary cirrhosis & 1 \\
Pericholangitis & 2 \\
Normal & 1 \\
\hline
\end{tabular}

obtained using a Menghini needle; 25 biopsy specimens were available for review. The liver tissue was fixed in $10 \%$ buffered formalin and embedded in paraffin, and $6-10 \mu \mathrm{m}$ sections were stained with haematoxylin and eosin, periodic acid Schiff with and without diastase, Van Gieson, Shikata's orcein for copper binding protein, Perls's Prussian blue for haemosiderin, and Gordon and Sweets' silver stain for reticulin. The indirect immunoperoxidase method was used to show $\alpha_{1}$-antitrypsin.

All liver biopsies were initially reported by two pathologists who were unaware of the clinical diagnosis. The biopsies were then reviewed with full knowledge of the clinical and radiological features.

\section{Results}

Table 1 shows the initial histological diagnoses of the 16 patients with ulcerative colitis and primary sclerosing cholangitis. Primary sclerosing cholangitis was initially diagnosed in only half of the patients. This was based on the finding of periductal fibrosis even in the absence of portal tract inflammation (Fig. 1).

A more detailed study of all the liver biopsies was therefore undertaken to delineate other features that occur in primary sclerosing cholangitis.

\section{PORTAL TRACT PATHOLOGY (Table 2)}

The characteristic feature of primary sclerosing cholangitis-namely, concentric fibrosis around small and medium sized interlobular ducts-was shown in half of the patients (Fig. 1). In the same biopsy this lesion can coexist with reduction or total loss of individual interlobular ducts and bile ductular proliferation. The residue of complete bile duct destruction is a small portal tract scar. In 15 cases, however, degenerative changes in bile duct epithelial cells were present. This was associated with focal infiltration of the epithelium by lymphocytes and macrophages, which are not found to an appreciable degree in normal ducts. Epithelial degeneration was characterised by variation in nuclear size, loss of polarity of epithelial cells, indistinct cytoplasmic borders, and focal disruption or duplication of the basement membrane, or both (Figs. 2 and 3).

The focal chronic cholangiolytic process was unre-

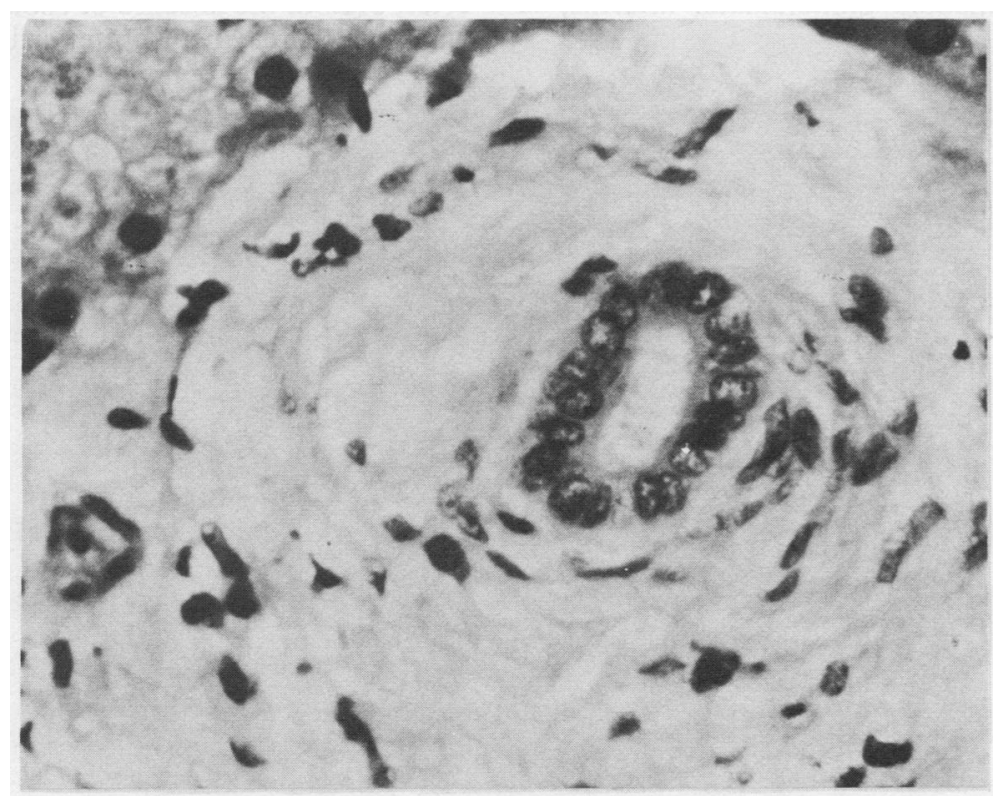

Fig. 1 Concentric fibrosis is seen around a small interlobular bile duct. There is no appreciable inflammation in this portal tract. $\times 500$. 
Table 2 Portal tract pathology in patients with primary sclerosing cholangitis

\begin{tabular}{|c|c|c|c|c|c|c|c|}
\hline \multirow[t]{2}{*}{ Structure } & \multirow[t]{2}{*}{ Feature } & \multirow[t]{2}{*}{ No of cases } & \multirow[t]{2}{*}{ Focal } & \multirow[t]{2}{*}{ Diffuse } & \multicolumn{3}{|c|}{ Severity } \\
\hline & & & & & + & ++ & +++ \\
\hline Bile ducts & $\begin{array}{l}\text { Periductal fibrosis } \\
\text { Proliferation } \\
\text { Degeneration } \\
\text { Reduction } \\
\text { Absence }\end{array}$ & $\begin{array}{r}8 \\
8 \\
15 \\
4 \\
2\end{array}$ & $\begin{array}{r}8 \\
7 \\
14 \\
4 \\
2\end{array}$ & $\begin{array}{l}-1 \\
1 \\
-\end{array}$ & $\begin{array}{r}5 \\
5 \\
10 \\
3 \\
-\end{array}$ & $\begin{array}{l}3 \\
3 \\
5 \\
1 \\
\end{array}$ & $\begin{array}{l}0 \\
0 \\
0 \\
0 \\
\end{array}$ \\
\hline Stroma & $\begin{array}{l}\text { Oedema } \\
\text { Fibrosis } \\
\text { Inflammatory infiltrates }\end{array}$ & $\begin{array}{r}9 \\
15 \\
15\end{array}$ & $\begin{array}{r}9 \\
13 \\
10\end{array}$ & $\begin{array}{l}- \\
2 \\
5\end{array}$ & $\begin{array}{r}9 \\
5 \\
10\end{array}$ & $\begin{array}{l}0 \\
7 \\
5\end{array}$ & $\begin{array}{l}0 \\
3 \\
0\end{array}$ \\
\hline
\end{tabular}

Of 16 proved cases of primary sclerosing cholangitis one had a normal liver biopsy specimen.

lated to the degree of bile duct proliferation or portal tract inflammation. The concentric periductal fibrosis of primary sclerosing cholangitis was absent in half of the patients, but there were histological features indicative of focal inflammation affecting the biliary tree in all but one patient. Proliferation, reduction, or total loss of bile ducts could coexist within the same section.

In the portal tract connective tissue there was a mild to pronounced infiltrate of lymphocytes, monocytes, occasional plasma cells, eosinophils, and polymorphonuclear leucocytes. The last cell type predominated when cholestasis and ascending cholangitis were present. This inflammatory response was seen in association with the duct changes described above (Figs. 1-4). There was no evidence of epithelioid granulomata, arteritis, or phlebitis.
LIVER PARENCHYMAL PATHOLOGY (Table 3)

Sixty per cent of patients showed focal erosion of the limiting plate by mononuclear cells and polymorphonuclear leucocytes, which resulted in separation of hepatocytes, but rosette formation was absent. This was associated with focal bile ductular proliferation and formation of loose and oedematous connective tissue (Fig. 5). In the absence of liver cell degeneration it is possible that this type of inflammation in the periportal parenchyma represents a spill over of the chronic inflammatory reaction around damaged bile ducts. In this group of patients the histological lesions had been initially wrongly interpreted as chronic active hepatitis.

Another finding was the presence of foci of copper binding protein granules in periportal hepatocytes, even in the absence of cholestasis. Other features such as reactive Kupffer cells and non-specific

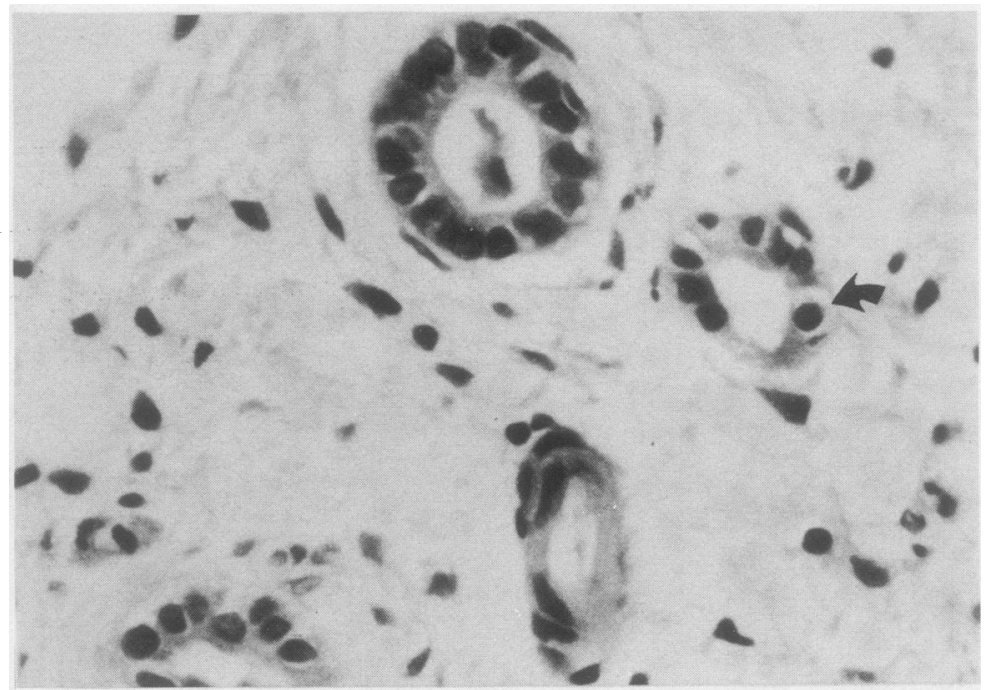

Fig. 2 Infiltration of bile duct epithelium by mononuclear cells (arrow) together with mild portal tract fibrosis and chronic inflammation. $\times 500$. 


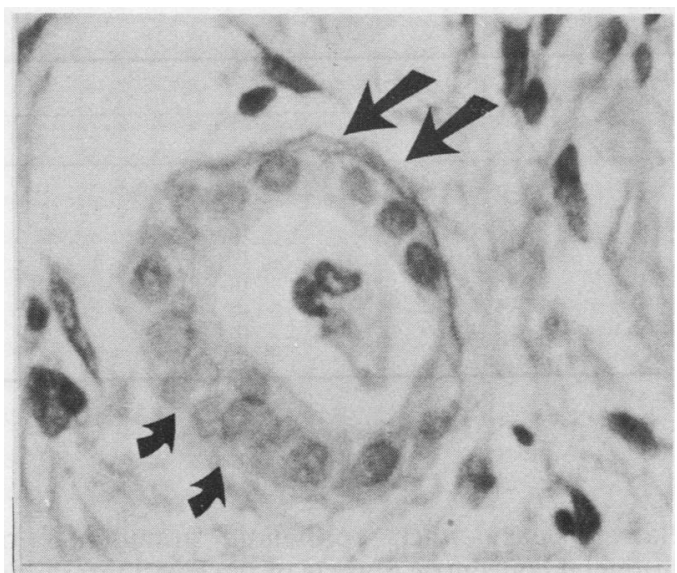

Fig. 3 Interlobular bile duct showing partial destruction of basement membrane (small arrows) and duplication of basement membrane (large arrows). Bile duct epithelium is stratified. Nuclei of some bile duct epithelial cells show irregularity in size and shape and pyknosis. $\times 800$.

chronic intralobular inflammation were found in most cases. Scattered acidophilic bodies and fatty infiltration of hepatocytes were also seen in a few patients.

In summary, the following combination of features is highly suggestive of primary sclerosing cholangitis even when concentric fibrosis around intralobular bile ducts is not detected: reduction and absence of bile ducts; proliferation of bile ductules; degeneration of bile duct epithelium associated with a mononuclear cell infiltrate; erosion of the limiting plate (in the absence of rosettes); focal accumulation of copper binding protein; chronic lobular inflammation; and Kupffer cell hyperplasia. On the basis of these criteria, a probable diagnosis of primary sclerosing cholangitis was made in 14 of 16 cases with radiologically proved disease. In the two remaining cases the liver biopsy was normal in one and thought to be chronic active hepatitis in another.

\section{Discussion}

A wide range of hepatic histological abnormalities has been found in patients with chronic ulcerative colitis. ${ }^{513-15}$ Fatty infiltration and pericholangitis are the most common lesions, and it has been claimed that sclerosing cholangitis, bile duct carcinoma, chronic active hepatitis, and cirrhosis are relatively rare. ${ }^{11} 1416-18$ It is now clear that primary sclerosing cholangitis is the most common form of liver disease associated with ulcerative colitis. ${ }^{67}$ In this study we have confirmed that concentric fibrosis around some interlobular bile ducts is characteristic of primary sclerosing cholangitis. We have also shown, however, that other features, even in the absence of concentric fibrosis, strongly suggest a diagnosis of prim-

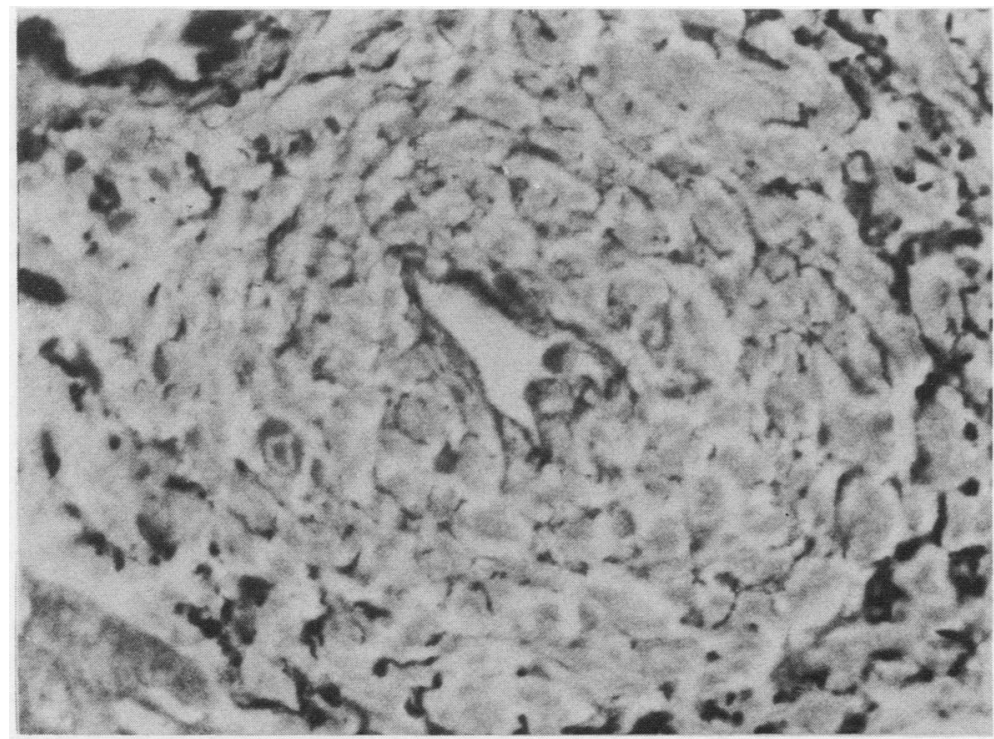

Fig. 4 Portal tract scar in primary sclerosing cholangitis. The epithelium of an interlobular bile duct has completely disappeared and the duct is surrounded by a collagenous scar. $\times 800$. 
Table 3 Liver parenchymal pathology in primary sclerosing cholangitis*

\begin{tabular}{|c|c|c|c|c|c|c|}
\hline \multirow[t]{2}{*}{ Feature } & \multirow[t]{2}{*}{ No of cases } & \multirow[t]{2}{*}{ Focal } & \multirow[t]{2}{*}{ Diffuse } & \multicolumn{3}{|c|}{ Severity } \\
\hline & & & & + & ++ & +++ \\
\hline $\begin{array}{l}\text { Erosion of limiting plate } \\
\text { Copper binding protein } \\
\text { Cholestasis } \\
\text { Acidophilic bodies } \\
\text { Chronic lobular inflammation } \\
\text { Fatty infiltration } \\
\text { Reactive Kupffer cells } \\
\alpha_{1} \text {-antitrypsin granules } \dagger\end{array}$ & $\begin{array}{r}9 \\
9 \\
2 \\
2 \\
11 \\
4 \\
16 \\
2\end{array}$ & $\begin{array}{r}9 \\
7 \\
0 \\
2 \\
11 \\
4 \\
0 \\
2\end{array}$ & $\begin{array}{l}\overline{2} \\
2 \\
0 \\
0 \\
0 \\
0 \\
0\end{array}$ & $\begin{array}{r}5 \\
4 \\
0 \\
2 \\
11 \\
2 \\
16 \\
0\end{array}$ & $\begin{array}{l}4 \\
3 \\
0 \\
0 \\
0 \\
2 \\
0 \\
0\end{array}$ & $\begin{array}{l}0 \\
2 \\
2 \\
0 \\
0 \\
0 \\
0 \\
2\end{array}$ \\
\hline
\end{tabular}

* Sixteen cases were studied.

†These were found in periportal hepatocytes.

ary sclerosing cholangitis. These are the combined presence of bile ductular proliferation and reduction or absence of bile ducts; degeneration of bile duct epithelial cells associated with diffuse mononuclear and polymorphonuclear cell infiltration; accumulation of copper binding protein in peripheral hepatocytes; spill over of inflammatory cells into the lobule with erosion of the limiting plate in the absence of rosette formation; and the production of young connective tissue in portal tracts. Not all of these features are present in portal tracts in any given biopsy.

It is important to differentiate sclerosing cholangitis from a wide range of chronic inflammatory liver diseases such as primary biliary cirrhosis, chronic active hepatitis, and chronic large bile duct obstruction or stenosis. The distinction between primary biliary cirrhosis and primary sclerosing cholangitis is relatively easy when epithelioid granulomas or periductal concentric fibrosis of the small interlobular ducts are present. In the absence of these features the location of the inflammatory cell infiltrate is informative. In primary biliary cirrhosis it is focal around bile ducts, although in primary sclerosing cholangitis the infiltrate is diffuse and not centred on bile ducts. The marginal proliferation of bile ductules along the terminal plate with loss of the main interlobular duct was not seen in our patients with primary sclerosing cholangitis. Sclerosing cholangitis can be mistaken for chronic active hepatitis, ${ }^{3610}$ but in our series it was distinguished by diffuse infiltration within the portal tracts, the absence of rosettes, and the presence of positive features such as periductal fibrosis.

The distinction from long standing extrahepatic

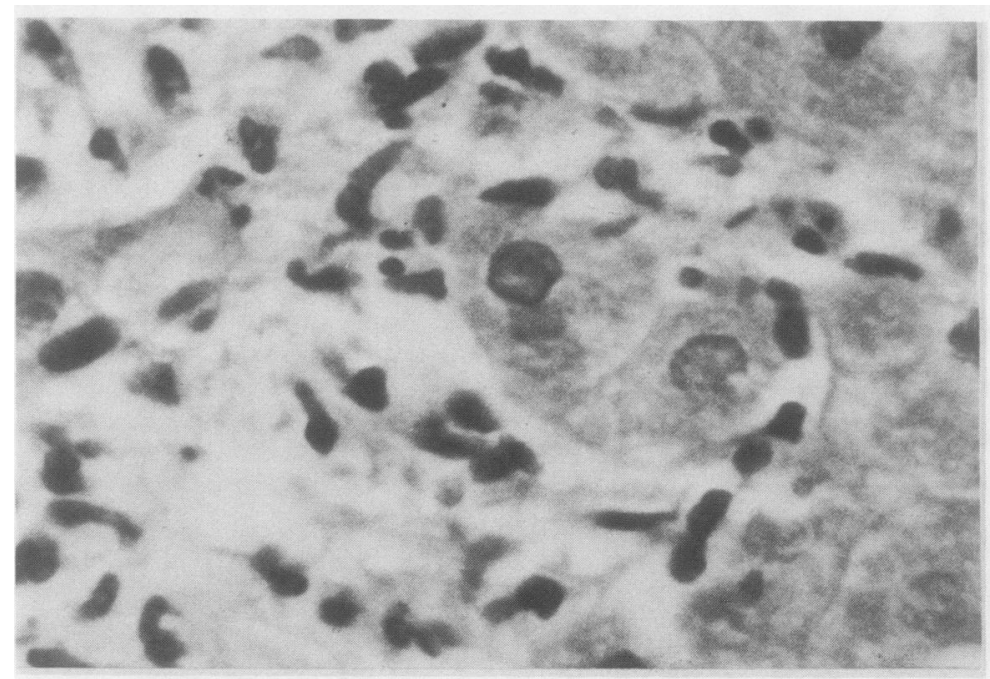

Fig. 5 Piecemeal necrosis in primary sclerosing cholangitis. The limiting plate is eroded and hepatocytes are separated by oedematous fibrous tissue infiltrated by acute and chronic inflammatory cells. $\times 800$. 
bile duct obstruction may pose problems because chronic portal inflammation, bile duct proliferation, and occasionally periductal fibrosis are also present. ${ }^{19-22}$ The main distinguishing feature is that in large duct obstruction all portal tracts are more or less uniformly affected while in primary sclerosing cholangitis the disease is focal.

Sclerosing cholangitis is a primary chronic nongranulomatous destructive inflammation, which randomly affects the biliary tree in a segmental manner; the severity varies from patient to patient. The histological progression of sclerosing cholangitis is not clear, although secondary biliary cirrhosis and carcinoma of the bile ducts may develop in patients with inflammatory bowel disease and long standing primary sclerosing cholangitis. ${ }^{36} \mathrm{Kern}^{14}$ considered that pericholangitis had a benign course, although patients may develop cirrhosis, which he describes as "bridging portal hepatofibrosis." It is possible that patients with ulcerative colitis and pericholangitis do, in fact, suffer from primary sclerosing cholangitis. Lefton and Winkelman found that six of eight patients with pericholangitis and ulcerative proctocolitis had abnormalities of the bile ducts on endoscopic retrograde cholangiopancreatography. ${ }^{23}$ Other workers have also found the same. ${ }^{24} 25$

The results of one study indicate that even in the absence of radiological evidence of sclerosing cholangitis, histologically identical lesions are seen in the liver. ${ }^{13}$ It may be that intrahepatic biliary duct disease precedes the stenosis of the larger biliary tree or that mild forms of the disease exist without necessarily progressing to radiologically evident sclerosing cholangitis. The fact that one of our patients had normal hepatic morphology could be explained on the basis that sclerosing cholangitis is a segmental lesion.

HAS is in receipt of a MRC Training Fellowship. PG is a Planchart scholar at Green College, the Nuffield Department of Pathology, Oxford University.

\section{References}

' Thorpe MEC, Scheuer PJ, Sherlock S. Primary sclerosing cholangitis, the biliary tree and ulcerative colitis. Gut 1967;8:435-48.

${ }^{2}$ Meyers RN, Cooper JH, Pallis N. Primary sclerosing cholangitis. Am J Gastroenterol 1970;53:524-38.

${ }^{3}$ Wiesner RH, La Russo NF. Clinicopathologic features of the syndrome of primary sclerosing cholangitis. Gastroenterology 1980;79:200-6.

${ }^{4}$ Diseases of the liver and biliary tract: Standardization of nomenclature, diagnostic criteria and diagnostic methodology. Fogarty International Center Proceedings No 22. (DHEW publication number (NIH). 76-725.)

${ }^{5}$ Vierling JM. Hepatobiliary complications of ulcerative colitis and Crohn's disease. In: Zakim D, Boyer TD, eds. Hepatology. Philadelphia: WB Saunders, 1982:797-824.

- Chapman RWG, Arborgh BA, Rhodes JM, et al. Primary sclerosing cholangitis: a review of its clinical features, cholangiography and hepatic histology. Gut 1980;21:870-7.

'Shepherd HA, Selby W, Chapman RW, et al. Ulcerative colitis and persistent liver dysfunction. $Q J$ Med 1983;52:503-13.

${ }^{8}$ Warren KW, Athanassiades S, Mouge JI. Primary sclerosing cholangitis. Am J Surg 1966;111:23-38.

' Kimmestiel P, Large HLJz, Verner HD. Liver drainage in ulcerative colitis. Am J Pathol 1952;28:259-89.

"Schwartz SI, Dale WA. Primary sclerosing cholangitis. Review and report of 6 cases. Arch Surg 1958;77:439-51.

"Stauffer M, Sauer WG, Dearing W, Baggenstoss AH. The spectrum of cholestatic hepatic disease. JAMA 1965;191:829-37.

${ }_{12}$ Mistilis PS. Pericholangitis and ulcerative colitis I. Pathology, etiology, pathogenesis. Ann Int Med 1965;63:1-25.

${ }^{13}$ Ludwig T, Barham S, La Russo NF, et al. Morphological features of chronic hepatitis associated with primary sclerosing cholangitis and chronic ulcerative colitis. Hepatology 1981;1:632-40.

${ }^{14}$ Kern F. Hepatobiliary disorders in inflammatory bowel disease. In: Popper H, Schaffner F, eds. Progress in liver diseases, vol V. New York: Grune and Stratton, 1976:575-89.

${ }^{15}$ Kern F. Hepatobiliary disorders in inflammatory bowel disease. In: Schiff L, Schiff ER, eds. Diseases of the liver. 5th ed. Philadelphia: JB Lippincott, 1982:1603-14.

${ }^{16}$ Eade MN. Analysis of operative liver biopsy in 138 consecutive patients having colectomy. Ann Int Med 1970;72:475-87.

${ }^{17}$ Perrett AD, Higgins G, Johnston $\mathrm{HH}$, et al. The liver in ulcerative colitis. $Q J$ Med 1971;40:211-38.

${ }^{18}$ Lupinetti M, Mehigan D, Cameron JC. Hepatobiliary complications of ulcerative colitis. Am J Surg 1980;139:113-8.

${ }^{19}$ Gall EA, Dobrogorski O. Hepatic alterations in obstructive jaundice. Am J Clin Pathol 1964;41:126-39.

${ }^{20}$ Poulsen H, Christoffersen P. Histological changes in liver biopsy from patients with surgical bile duct disorders. Acta Pathol Microbiol Scand [A] 1970;78:571-9.

${ }^{21}$ Morris JS, Gallo GA, Scheuer PJ, et al. Percutaneous liver biopsy in patients with large bile duct obstruction. Gastroenterology 1975;68:750-4.

${ }^{22}$ Afroudakis A, Kaplowitz N. Liver histopathology in chronic common bile duct stenosis due to chronic alcoholic pancreatitis. Hepatology 1981;1:65-72.

${ }^{23}$ Lefton HB, Winkelman EI. Endoscopic retrograde cholangiographic evaluation of sclerosing cholangitis. Cleve Clin $Q$ 1974; 1: 143-7.

${ }^{24}$ Blackstone MO, Nemchausky BA. Cholangiographic abnormalities in ulcerative colitis associated pericholangitis which resemble sclerosing cholangitis. Am J Dig Dis 1978;23:579 85.

${ }^{25}$ Schrumpf E, Elgjo K, Fausa D, et al. Sclerosing cholangitis in ulcerative colitis. Scand. J Gastroenterol 1980;15:689-97.

Requests for reprints to: Professor J O' D McGee, Nuffield Department of Pathology, John Radcliffe Hospital, Oxford OX3 9DU, England. 